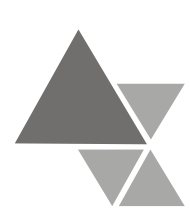

\title{
A Dimensão Rural da Insegurança Alimentar: Transformações nas Práticas de Autoconsumo entre Famílias Rurais do Extremo Sul Gaúcho
}

\author{
Flávio Sacco dos Anjos ${ }^{1}$, Nádia Velleda Caldas ${ }^{2}$, Wanda Griep Hirai ${ }^{3}$
}

\section{Resumo}

O artigo é baseado em pesquisa qualitativa realizada no extremo sul do Rio Grande do Sul e explora as transformações sobre as práticas de autoconsumo no âmbito da agricultura familiar, motivadas, essencialmente, pelo processo de mercantilização da agricultura e da vida rural. As práticas de autoconsumo expressam a matriz cultural das famílias rurais, em que pese o valor simbólico atribuído aos produtos gerados no próprio estabelecimento rural, em comparação com o que é adquirido externamente no comércio, ou em outras unidades de produção. A pesquisa de campo foi realizada com trinta estabelecimentos de agricultura familiar, cuja atividade comercial principal das famílias residia, fundamentalmente, na produção de leite, pêssego e fumo. Os autores discutem os impactos da mercantilização da agricultura sobre as práticas de autoconsumo.

Palavras chaves: agricultura familiar, autoconsumo, segurança alimentar.

\begin{abstract}
The article is based on carried through qualitative research in the southern extreme of the Rio Grande do Sul state and explores the transformations on the practical ones of self-consumption production in the context of familiar agriculture, essentially, under the impacts of the process of commoditization of agriculture and the rural life. The self-consumption practices present a cultural matrix among rural families, in spite of the symbolic value attributed to products generated within the very rural establishment, as compared to the ones which are acquired externally in usual commerce or from other production units. The field-work was performed within thirty family agricultural establishments whose main commercial activity lies on the milk, peach and tobacco production. The authors discusses the impacts of the commoditization of agriculture on the practical of self-consumption production.
\end{abstract}

Key words: family agriculture, self-consumption production, food security.

\footnotetext{
${ }^{1}$ Professor do Departamento de Ciências Sociais Agrárias e dos Programas de Pós-Graduação em Sistemas de Produção Agrícola Familiar e de Ciências Sociais (UFPel), Pesquisador do CNPq. Endereço para contato: Faculdade de Agronomia Eliseu Maciel, UFPel, Cx. Postal 354, CEP 96010-900, Pelotas, RS. Telefone: (53) 3275.7256, Fax: (53) 3275.9031. E-mail: fsacco2000@yahoo.com.br.

${ }^{2}$ Doutoranda do Programa de Pós-Graduação em Sistemas de Produção Agrícola Familiar e Professora do Departamento de Ciências Sociais Agrárias (UFPel), Bolsista do CNPq. E-mail: velleda.nadia@gmail.com.

${ }^{3}$ Mestre em Ciências pelo Programa de Pós-Graduação em Sistemas de Produção Agrícola Familiar e Professora da UCPEL.Email: wanda.hirai@gmail.com.
} 


\section{Introdução}

O tema da segurança alimentar assume, na atualidade, um lugar destacado tanto no plano do processo de intervenção estatal brasileiro quanto no âmbito da agenda de pesquisa sócio-política. No segundo caso, convergimos no entendimento de que não obstante a grande importância atribuída à análise de impactos de políticas públicas voltadas ao combate à insegurança alimentar, pouca atenção tem sido dada a esse tema no âmbito rural. Outro aspecto que merece ser enfatizado, no sentido de demarcar o foco do presente artigo, recai no entendimento de que pobreza e insegurança alimentar são reiteradamente tomadas como fenômenos mutuamente conectados.

Todavia, o fato de grupos rurais de muitas zonas deprimidas do país contarem com escassos rendimentos monetários não pode ocultar o reconhecimento de que existe uma complexa rede de questões envolvendo o esforço dos indivíduos por assegurar uma dieta alimentar satisfatória. Convergimos com Antônio Cândido, em seu importante estudo sobre esse tema, segundo o qual, para cada cultura há uma técnica de viver, da qual a alimentação faz parte. Saciar a fome e garantir uma dieta satisfatória torna-se o centro de um dos mais vastos complexos sócio-culturais, abrangendo atos, normas, símbolos e representações. A obtenção da comida confunde-se, portanto, com a gênese de quase todas as instituições sociais ${ }^{[1]}$.

O objetivo do presente artigo é o de contribuir nesse debate, com base em estudos desenvolvidos recentemente sob apoio financeiro do CNPq. Trata-se de investigar em que medida as práticas de autoconsumo vêm sendo modificadas a partir das transformações operadas no espaço rural do extremo sul gaúcho, particularmente em função dos efeitos produzidos pela especialização produtiva e pela mercantilização da agricultura.

Após essa breve introdução, o artigo se divide em quatro outras seções. A próxima é dedicada a explicitar duas noções chaves (agricultura familiar e autoconsumo), reciprocamente imbricadas para 0 desenvolvimento da abordagem, ao passo que a terceira seção descreve a metodologia adotada na realização da pesquisa. A quarta seção trata do tema da mercantilização da agricultura e de seus desdobramentos sobre a dinâmica da agricultura familiar no Sul do Brasil, enquanto a quinta e última seção explora as transformações nas práticas de consumo no marco da mercantilização da agricultura.

\section{A agricultura familiar e a importância da produção de autoconsumo}

É sobretudo na segunda metade dos anos 1990 que a noção correspondente à agricultura familiar foi introduzida, quase que simultaneamente, na cena acadêmica e política brasileira. Nesse sentido, como recorda Schneider ${ }^{[2]}$, "a adoção da expressão parece ter sido encaminhada como uma nova categoriasíntese pelos movimentos sociais do campo".

Entendemos a agricultura familiar como uma forma social de produção que apresenta uma lógica peculiar de funcionamento, cuja racionalidade orienta-se na busca por assegurar a reprodução social de seus membros. Para Gasson e Errington ${ }^{[3]}$, ela 
pode ser definida a partir de alguns traços fundamentais, quais sejam: a) a gestão é feita pelos proprietários; b) os responsáveis pelo empreendimento estão ligados entre si por laços de parentesco; c) o trabalho é fundamentalmente familiar; d) o patrimônio pertence à família; e) o patrimônio e os ativos são objeto de transferência intergeracional no interior da família e, finalmente, f) os membros da família vivem na unidade produtiva.

Mas, é importante frisar que quando nos referimos a agricultores familiares, não temos em mente apenas produtores, mas sujeitos históricos que reproduzem valores de uma cultura, que em maior ou menor medida, é preservada no Sul do Brasil, a qual poder-seia denominar como tipicamente camponesa ${ }^{4}$. A carga de subjetividade nesse universo simbólico se expressa, entre outros aspectos, nas formas de transmissão do patrimônio fundiário $^{[4]}$, no sentido atribuído às relações de parentesco $^{[5]}$ ou à comida produzida pela família no próprio lote em detrimento da parcela adquirida junto ao comércio local ou regional.

O reconhecimento desses atributos há que ser tomado como indicativo dos vínculos que unem o camponês ao agricultor familiar, enquanto formas sociais de produção. Não obstante, ambas categorias guardam singularidades que devem ser levadas em

\footnotetext{
${ }^{4}$ Essa cultura tipicamente camponesa está presente no universo social e simbólico do colono do Brasil meridional, na multiplicidade de etnias (alemães, italianos, poloneses, pomeranos, franceses, austríacos, etc) que conformam as comunidades rurais, particularmente nos Estados do Rio Grande do Sul e Santa Catarina, cujo surgimento, durante o século XIX, configura o que Wanderley ${ }^{[7]}$ denomina de processo de "campesinação".
}

conta como forma de contornar certas ambigüidades. Para tanto, servimo-nos do estudo realizado por Lamarche ${ }^{[6]}$ que considera que toda exploração camponesa é de caráter familiar, mas, ao contrário, nem todas as explorações familiares são de caráter camponês. O eixo de definição reside no maior ou menor grau de vinculação aos mercados, fato que repercute, evidentemente, no maior ou menor nível de autonomia destas unidades de produção em relação ao ambiente social em que se encontram inseridas. No modelo adotado por Lamarche as explorações tipicamente camponesas seriam aquelas em que a mão-de-obra ocupada na unidade de produção é exclusivamente familiar, ao passo que nas explorações identificadas como de agricultura familiar a força de trabalho é essencialmente familiar, havendo a presença, em maior ou menor medida, de contratação de trabalhadores externos em caráter eventual.

Há, não obstante, um outro conceito que deve ser discutido para os propósitos desse artigo. O autoconsumo é objetivamente definido por Leite ${ }^{[8]}$ como sendo uma fração da produção agropecuária (agrícola, pecuária, extrativista e aquela que deriva de produtos primários beneficiados), que se realiza no estabelecimento rural e se destina ao consumo alimentar dos membros da família e, inclusive, à alimentação animal e a outros usos na atividade produtiva.

Parte-se do entendimento de que parcela expressiva da produção científica orientada a investigar os processos atinentes à dinâmica da agricultura familiar concede escassa importância a essa dimensão. A tendência economicista, como advertiu Woortman $^{[9]}$, vê estritamente o campesinato e, 
na nossa acepção, a agricultura familiar, como um modo de produção com sua lógica própria ou como o resultado de determinações impostas pela dinâmica do capital. Nesse contexto, a ênfase recai sobre a dimensão comercial da exploração familiar e sobre a funcionalidade dessa forma de produção à acumulação do capital.

A questão do autoconsumo foi enfocada por Garcia $\mathrm{Jr}^{[10]}$ ao descrever o "princípio da alternatividade" que carregam certos cultivos, especialmente a mandioca, a qual pode ser comercializada, consumida in natura pela família, convertida em farinha ou retida para comercialização posterior. Assim, a comercialização da produção não é analisada como se fora simplesmente um "excedente" em relação às necessidades da família, mas como material da complementariedade existente entre o produzir com objetivos mercantis e o atendimento das necessidades alimentares da família.

Parece óbvio que a marca da alternatividade não pode ser transferida a um amplo leque de atividades que são atualmente centrais à dinâmica de reprodução social da agricultura familiar no Brasil meridional, como é o caso do tabaco, soja, pêssego, uva, avicultura, suinocultura, entre outras, regidas pelo caráter intensivo dos processos produtivos. A produção de alimentos para o consumo familiar representa o símbolo maior acionado pelos colonos para "diferenciá-los do simples operário" que vive só do salário, como referiu Seyferth ${ }^{[11]}$.

Há por certo, um expressivo número de trabalhos que evocam o impacto produzido por novos hábitos de consumo alimentar.
Tanto na Ásia quanto na África, como alude Mintz $^{[12]}$, "as dietas rurais incorporam mais gêneros de primeira necessidade do que as dietas urbanas" por uma série de fatores que incluem a crescente incorporação de mulheres ao mundo do trabalho. Essas supostas mudanças também aparecem associadas ao fato de que o consumo alimentar implica um processo de distinção e classificação social nos termos propostos por Bourdieu ${ }^{[13]}$. Com base nesse entendimento, a crescente incorporação de produtos industrializados poderia ser tomada como expressão dessa suposta tendência de ascensão social por parte de famílias rurais, acostumadas às vicissitudes do conhecido "déficit de cidadania".

Há, destarte, um conjunto de vetores que vem impactando sobre a dimensão do autoconsumo no contexto das famílias rurais do Brasil, o qual importa destacar para o argumento central que sustenta o presente artigo. Antes, porém, cabe explicitar os procedimentos metodológicos de que nos servimos na realização dessa pesquisa.

\section{Metodologia}

A pesquisa de que resultou o presente artigo realizou-se a partir de trabalho de campo desenvolvido durante o primeiro semestre de 2007 em comunidades rurais de três municípios do extremo sul gaúcho (Pelotas, São Lourenço do Sul e Canguçu), precisamente localizados na Serra dos Tapes, consistindo numa região marcada pela presença de explorações familiares.

Em cada município foram selecionados dez (10) agricultores familiares para aplicação de entrevista em profundidade, com base em roteiro prévio de perguntas, cujo 
foco essencial recaiu na dinâmica das práticas de autoconsumo e na dimensão simbólica dessa atividade. Com base nesse procedimento, reuniu-se um amplo banco de dados resultantes da transcrição de trinta (30) entrevistas realizadas nos estabelecimentos rurais, além de outras dez (10) entrevistas efetuadas com extensionistas rurais e agentes de desenvolvimento ligados a organizações nãogovernamentais e associações comunitárias.

A escolha das famílias a serem entrevistadas ocorreu com base em parâmetro que levou em conta a principal atividade comercial da unidade de produção, considerando os principais produtos gerados nesses estabelecimentos familiares (fumo, leite e pêssego). Tratava-se de assegurar que as explorações entrevistadas efetivamente refletissem a realidade da agricultura familiar nessa região do Rio Grande do Sul.

A solução encontrada foi seguir as indicações das organizações sócio-técnicas e atores sociais que atuam no universo da agricultura familiar na região, quais sejam, os escritórios da Empresa de Assistência Técnica e Extensão Rural (EMATER) do Rio Grande do Sul nos municípios investigados, agentes da Federação dos Agricultores Familiares (FETRAF) e União das Associações Comunitárias do Interior de Canguçu (UNAIC). Os agricultores familiares foram pré-selecionados a partir das informações sobre o recorte que nos interessava para o objeto da pesquisa. A lista preliminar era apresentada a outros agentes com o objetivo de avaliar em que medida esses produtores espelhavam o perfil regional, segundo as atividades produtivas predominantes, nível tecnológico, escala de produção, disponibilidade de bens, sistemas de produção, entre outros atributos.

Essas indicações dos agentes de desenvolvimento foram fundamentais em face do elevado número de unidades familiares de produção existentes na região investigada. De acordo com dados do Incra-Sade ${ }^{[14]}$, os municípios de Pelotas, São Lourenço do Sul e Canguçu possuem, respectivamente, 3.555, 3.806 e 8.831 estabelecimentos de caráter familiar, cuja vocação produtiva converge para as atividades anteriormente referidas.

Os depoimentos que serão evocados nas partes subsequentes desse artigo foram colhidos com base no uso do gravador, mediante consentimento prévio dos entrevistados. As entrevistas foram agendadas previamente por telefone, ou por meio de convite realizado pelas organizações aludidas anteriormente. A busca por realizar uma aproximação rigorosa com a realidade em que se encontram imersas as famílias rurais obrigou a que se tivesse de percorrer um total de dezesseis (16) distritos distribuídos numa ampla zona que recobre os três municípios pesquisados.

O contato direto com os agricultores familiares e suas famílias, converteu-se num espaço fecundo para a apreensão do cotidiano das comunidades rurais, oportunizando a ampliação da participação de sujeitos, considerando-se que quando a entrevista ocorreu com o chefe da família, foi solicitada a presença e participação da esposa durante a realização das entrevistas. 


\section{Contornos da Mercantilização da agricultura no extremo sul gaúcho}

As então províncias do Rio Grande do Sul e Santa Catarina foram o destino principal de um processo de colonização iniciado com a vinda de imigrantes europeus não-ibéricos durante o século XIX. A imigração alemã se iniciou em 1824, quando chegaram as primeiras famílias à recém fundada Colônia de São Leopoldo, no vale do Rio dos Sinos, próxima à capital (Porto Alegre). Mas, como advertiu Seyferth ${ }^{[15]}$, sob o rótulo de "colonos alemães" englobam-se todos os imigrantes procedentes da Alemanha, Áustria ou Polônia de fala germânica. A imigração italiana ocorre somente a partir de 1875 , tendo como destino primordial a região serrana gaúcha e os campos de cima da serra. A conhecida prosperidade dos núcleos coloniais é atribuída a uma série de fatores, entre os quais o de haverem surgido "longe das regiões de grandes propriedades luso-brasileiras empenhadas na criação de gado,"[15].

Sobre esse aspecto, é crucial mencionar que no extremo sul gaúcho o processo de colonização com imigrantes europeus (alemães, pomeranos, italianos e franceses) só irá ocorrer na segunda metade do século XIX, numa região marcada pelo peso do latifúndio e da pecuária extensiva. Coincidentemente, comemora-se hoje os 150 anos da imigração germânica, cujo processo de colonização, de natureza eminentemente privada, surgiu como um negócio promissor que converteu a Serra dos Tapes, que se estende pelos municípios de São Lourenço do Sul, Pelotas e Canguçu, no locus do assentamento dos primeiros colonos nesse território. Por meio de contrato firmado com o
Governo Imperial, o empresário alemão Jacob Rheigantz converteu terras devolutas em objeto do assentamento das famílias em lotes de aproximadamente 25 hectares.

Não nos parece um exagero afirmar que a constituição desses núcleos coloniais representou o surgimento de um verdadeiro "enclave" da agricultura de base familiar em meio ao império da oligarquia regional ligada à pecuária extensiva e à produção do charque ${ }^{5}$.

O campesinato que emergiu no extremo sul gaúcho dedicou-se à policultura $\mathrm{e}$ à pecuária de pequena escala, sobretudo para atender ao crescente mercado de consumo urbano de Pelotas e região. Além do "ouro branco" ${ }^{6}$ das colônias ${ }^{7}$, o rol de artigos incluía produtos que literalmente desapareceram no período subseqüente por conta de transformações a que posteriormente abordaremos. Desse rol fazem parte o alpiste, alfafa, piretro, cevada, aveia, marmelo, figo, trigo, batata inglesa, feijão, milho, cebola, bem como os produtos derivados da transformação

\footnotetext{
${ }^{5}$ Corresponde à produção de carne salgada em estabelecimentos produtivos (charqueadas) e que foi, durante os séculos XVIII e XIX o esteio essencial da economia do extremo sul gaúcho. O charque era produzido pela mão-de-obra escrava e exportado para outras regiões do Brasil e do mundo.

${ }^{6}$ A expressão em epígrafe foi utilizada por Roche ${ }^{[16]}$ ao referir-se à importância comercial assumida pelos derivados de porco, particularmente banha e toucinho no âmbito das colônias do Sul do Brasil.

7 No caso específico da Região Sul do Brasil, o termo "colônia" trata-se de uma expressão absolutamente polissêmica. Tanto pode significar uma dimensão agrária (entre 25 a 30 hectares), como toda uma região colonizada com imigrantes europeus. Mas além destes aspectos a expressão cobra importância sobretudo no âmbito das comunidades germânicas ("kolonie"), considerando, tal como mencionamos anteriormente, que foram estes os primeiros imigrantes não-ibéricos a desembarcar no sul do país. Como indicou Wanderley ${ }^{[7]}$, consistem em uma forma de campesinato.
} 
operada nos próprios estabelecimentos (laticínios, doces em pasta, conservas, etc.). O auge das colônias coincidiu com o alto nível de diversificação produtiva das comunidades rurais, responsáveis por engendrar as bases de uma indústria rural, de natureza artesanal, mas bastante importante à época. Dela fazem parte os moinhos coloniais, as primeiras cantinas de vinho e, sobretudo, as primeiras indústrias de conservas de pêssego e de aspargo.

Conforme advertiu Grando ${ }^{[17]}$, as origens da indústria de conservas vegetais de Pelotas estão nas fábricas artesanais rurais, que, "ao saírem do domínio camponês, se transformaram num parque de unidades industriais, o qual veio a ser o maior do gênero no Brasil". 8

Mas, esse processo de expansão industrial não se deu de forma aleatória ou espontânea, senão como resultado direto de uma política deliberada de incentivos fiscais e creditícios concedidos ao grande capital que se inicia durante a Era Vargas, com o monopólio estatal do trigo e o fechamento compulsório dos moinhos coloniais, ampliando-se, nas décadas subseqüentes, com a implantação do modelo de substituição de importações durante a ditadura militar. Com efeito, na região de Pelotas o período compreendido entre as décadas de 1950 a 1970 coincide com o surgimento de grandes indústrias conserveiras (compotas de pêssego, figo, aspargo, abacaxi), essencialmente situadas no perímetro urbano dessa cidade-pólo do sul gaúcho.

\footnotetext{
${ }^{8}$ Grando $^{[17]}$ descreve a importância da colônia francesa como responsável pelo surgimento das primeiras indústrias de pêssego na região que, durante os anos 1960, contava com mais de uma centena de empresas, de pequenas a grandes indústrias sediadas, fundamentalmente, no meio urbano de Pelotas.
}

Paradoxalmente, esse gênero de atividade industrial, surgido no âmbito das colônias e introduzido por imigrantes franceses, praticamente desapareceu nas áreas rurais, assestando um duro golpe às colônias do extremo sul gaúcho e à sobrevivência de muitos estabelecimentos familiares. $\mathrm{O}$ fechamento das agroindústrias rurais familiares responde às crescentes exigências da legislação sanitária e fiscal que, sob a alegação de preservar as condições de higiene das instalações e equipamentos, impuseram o fim desses empreendimentos.

Paulatinamente, os colonos vão se convertendo em produtores especializados de matéria-prima para a indústria de conservas, abandonando, definitivamente, um traço peculiar dessa forma social de produção, marcada pela policultura, diversificação de atividades e fontes de ingresso econômico. A simplificação dos sistemas de culturas é um fato inquestionável, conjuntamente com a subordinação a um mercado regional oligopsônico, que se impõe a um número estimado em 3,5 mil famílias rurais que passam a depender, em maior ou menor medida, de uma única fonte de ingresso econômico.

A modernização dos processos produtivos agrários traduz uma das dimensões em que passa a operar a mercantilização da agricultura e da vida social nas colônias do extremo sul gaúcho. É, por certo, um processo multifacetado $^{[18]}$, que assume distintos contornos no contexto em que operam as formas familiares de produção, as quais se tornam cada vez mais subordinadas e dependentes do comportamento dos mercados. A externalização da produção decorre da 
crescente dependência dos insumos e serviços adquiridos fora da exploração.

O aparecimento de novas necessidades materiais, a multiplicação de relações mercantis, a internacionalização da agricultura, com a crescente exposição às oscilações dos mercados, figuram em destaque como uma perversa tendência que conduz as famílias à especialização produtiva. $\mathrm{O}$ pêssego representa um exemplo emblemático de um fenômeno que alcança o Sul gaúcho até meados dos anos 1970.

Mas, a década de 1980 é marcada pela crise do setor conserveiro no extremo sul gaúcho, com a falência de muitas das grandes indústrias que processavam o pêssego, aspargo, morango, ervilha e outros produtos de extrema importância para a sobrevivência de milhares de famílias rurais que, como se disse anteriormente, haviam sido convertidas em produtores especializados de matérias-primas industriais. Boa parte deles encontraram na horticultura e produção de leite uma alternativa econômica, ao passo que um grande número de famílias sucumbiu em meio à crise e deixou o campo.

Outrossim, os anos noventa reservam um fato inusitado na cena rural dos municípios investigados e tem a ver com uma impressionante expansão da cultura do fumo. Essa atividade ocupa hoje mais de 182 mil famílias rurais nos Estados meridionais. O extremo sul gaúcho é uma das mais importantes regiões produtoras e a expansão do tabaco provoca a erradicação massiva de pomares de pêssego, de plantações de aspargo e de morango nas duas últimas décadas.
A partir de dados colhidos junto à Afubra $^{9[19]}$ foi possível chegar a uma estimativa que aponta para um total aproximado de 12 mil famílias envolvidas com a cultura do fumo na área que correspondeu à presente investigação. Essa atividade adquire um protagonismo inquestionável pelo fato de converter-se na principal (em muitos casos, exclusiva) fonte de ingresso econômico para muitas famílias.

O plantio do fumo requer um trabalho intensivo por parte de toda a família, ao longo de todo o ano ${ }^{[20]}$. A relação das famílias com as empresas é regida por contratos de integração vertical que, se por um lado, asseguram a compra antecipada da produção, por outro, obrigam as primeiras à adoção de um pacote tecnológico, fornecendo adubos, agrotóxicos e serviços (assistência técnica) que serão descontados ao final da safra. Mas, os produtores são igualmente responsáveis pela secagem do fumo colhido a campo, em estufas cuja construção é financiada pelas fumageiras, sendo essa uma etapa das mais complexas, face aos riscos que envolvem a qualidade da produção, a insalubridade da operação e a extensão das jornadas de trabalho.

No Sul do país os contratos de integração vertical articulam famílias e agroindústrias não somente no caso da produção de tabaco, mas em outros gêneros como é o caso da produção de frangos de corte, suinocultura e, mais recentemente, na produção de eucalipto.

\footnotetext{
9 A Afubra (Associação dos Fumicultores do Brasil) registra um crescimento de $93 \%$ no número de famílias produtoras de fumo entre a safra 1979/80 e 2006/07. Na última safra a área média plantada por família é estimada em 2,16 hectares
} 
$\mathrm{Na}$ área correspondente ao contexto do presente estudo existem atualmente, segundo dados do Incra-Sade ${ }^{[14]}, 16.192$ estabelecimentos de caráter familiar $(95,7 \%$ do total) dedicados a um conjunto bastante reduzido de atividades produtivas, se comparado com os primórdios do processo de colonização.

O período coincidente com a modernização conservadora (1965-1980), é marcado pelo aprofundamento da mercantilização da agricultura e da vida rural que, como foi referido, trouxe consigo inúmeros desdobramentos. A simplificação do sistema de culturas, a especialização e intensificação produtiva e o produtivismo são vistos como implicações diretas de um fenômeno no qual a perda de autonomia das famílias é incontestável, conferindo-lhes uma posição subordinada e cada vez mais vulnerável em relação aos mercados.

O crescimento no número de pomares de pêssego refletiu a expansão das indústrias de conservas durante esse período, paralelamente ao fechamento das agroindústrias artesanais rurais. Mas, esse gênero atravessou enormes dificuldades durante os anos oitenta, quando quase $90 \%$ das empresas fecharam suas portas, deixando as famílias em situação de total incerteza. Assim, a ascensão da cultura do fumo emoldura um novo ciclo de expansão e mercantilização dos espaços rurais do extremo sul gaúcho.

Outrossim, como a seguir veremos, no período anterior à mercantilização da agricultura, as práticas de autoconsumo eram marcadas pelo elevado grau de diversificação da pauta alimentar, em que pese a existência de uma dieta regida por produtos exclusivamente gerados nos limites da própria exploração.

\section{O declínio da produção de autoconsumo no contexto da mercantilização da agricultura}

A mercantilização da agricultura e dos espaços rurais no Brasil meridional se impõe de forma implacável sobre o universo da agricultura familiar. Como é sabido, a relação com o mercado é um aspecto intrínseco ao modo de vida dos descendentes de europeus no Sul do país, os quais desenvolveram um sistema de policultura articulado à criação de pequenos animais e de gado para a produção de leite.

Todavia, o que se quer chamar atenção nesse trabalho é que, no curso das transformações operadas a partir da modernização da agricultura, houve a eliminação de muitas explorações familiares que se mostravam incapazes de incorporar as inovações tecnológicas e o novo modo de produzir. As que conseguiram sobreviver, sob um ambiente invariavelmente desfavorável, foram lançadas numa perversa espiral que lhes conduziu à especialização produtiva. Deixamos isso claro na seção precedente, com base em alguns casos emblemáticos como no caso do pêssego e da plantação do tabaco.

Com isso, uma família que no passado contava com um amplo e diversificado conjunto de produções e fontes de ingresso econômico, passa agora a depender de uma única atividade produtiva, em meio ao cenário da especialização. 
O que aqui se busca evidenciar é que no afã de rentabilizarem o espaço produtivo e todas as energias existentes no seio da família para incrementar o nível de ingresso econômico, a produção destinada a atender o autoconsumo vem sendo sistematicamente sacrificada.

Antes de entrar na discussão dos dados colhidos na imersão realizada a propósito dessa pesquisa, convém reafirmar a importância dessa categoria - o autoconsumo como elemento idiossincrático da cultura camponesa que, no Sul do Brasil, cristaliza-se em torno do termo colono, em todas acepções correlatas. As práticas de autoprovisão são referidas de diversas formas, mas o que é recorrente é a sua centralidade nas representações do universo social dessas comunidades. Nesse sentido, "plantar para o gasto, em muitos casos, torna-se a característica mais evidente da condição de colono, e o define primordialmente como um produtor de alimentos para si e depois, se possível, para os outros "[11].

Mas essa marca de identidade do colono, em torno da qual sedimentaram-se certas representações, nas atuais circunstâncias, há que ser seriamente relativizada. Diversos vetores e circunstâncias conspiram para conformar esse quadro, tanto no plano externo quanto interno à exploração familiar. Parte-se aqui da premissa que estas famílias "adotam estratégias micro (de curto $e$ de longo prazo) como resposta a pressões macroeconômicas e políticas (preços, leis)". [21].

No plano externo são flagrantes as pressões emanadas das empresas do complexo agroindustrial, com quem as famílias assinam contratos de integração vertical. Exemplo disso pode ser visto a partir do que estabelece a líder mundial ${ }^{10}$ na produção de carnes de aves e derivados. No curso da presente investigação, fomos informados que a referida empresa proíbe as famílias de avicultores integrados de manterem aves de fundo de quintal ou criação de porcos em seus estabelecimentos. A justificativa decorre da preocupação com a sanidade dos lotes, criados em regime de confinamento, cujo número médio varia entre 16 e 21 mil aves por família ${ }^{11}$.

Se, por um lado, a empresa assegura a compra dos frangos, a assistência técnica e as condições de produção, por outra parte, impõe um rígido controle do processo e impede que a família preserve uma atividade fundamental, tanto na perspectiva da reprodução material de seus membros quanto do ponto de vista simbólico.

A mercantilização não se exprime apenas do ponto de vista da dinâmica que orienta a produção do frango, em meio à compra compulsória dos insumos vendidos pela empresa, os rigorosos controles da eficiência produtiva e de rentabilidade do negócio, mas inclusive por força do fato de que o abastecimento de artigos essenciais à vida doméstica (carne, ovos) é agora regido pela via da compra, não mais gerado pela família nos limites da própria exploração.

\footnotetext{
${ }^{10}$ Referimo-nos ao grupo francês Doux Frangosul ${ }^{[22]}$. Trata-se do maior produtor europeu de aves e de produtos transformados à base de carne de aves, com um faturamento equivalente a 1,2297 bilhões de Euros em 2006. Ver a propósito http://br.doux.fr/.

${ }^{11}$ Cada família produz entre 6 e 8 lotes, perfazendo aproximadamente $145 \mathrm{mil}$ aves/ano.
} 
$\mathrm{Na}$ atual conjuntura, produzir significa ampliação ilimitada do consumo de bens e serviços em relação aos quais os agricultores possuem uma reduzida margem de interferência, como revelam alguns depoimentos na analogia que os entrevistados realizam com o "tempo dos pais":

Isso aí totalmente mudou, né, a gente tava lembrando dos pais, era lavrado tudo a cavalo, plantava milho com matraca... Tinha uma sacola do lado, abria a cova e largava a semente $e$ plantava essa terra toda e tinha quatro junta de cavalo, mas naquela época dava o milho, sobrava um pouco mais, porque hoje o investimento é maior, comparando [...] Plantava batata sem agrotóxico e se colhia batata sem veneno. Hoje se tu vai plantá sem colocá nada, o bichinho come, né... Plantava-se muito feijão, se fazia roça nova. A gente tinha criação de porco, mas se tu tinha um lote de dez porco, fazia dinheiro [...]. Hoje tu tens cem porco e não sobrevive [...].

Hoje em dia a gente fica com nojo do serviço que tem. Nós plantava fumo, milho, feijão, batatinha para comer e batata doce a gente vendia, animal a gente criava e vendia também, galinha a gente criava para o consumo e porco pra vender... A gente era uma família humilde, nem luz elétrica tinha, nem geladeira, nem freezer, nem nada, a gente fazia toda carne coisa assim: a gente fritava e botava em uma lata de banha tudo assim, bem antigão... Ao passar o tempo a gente foi botando luz, a gente foi comprando as coisas e foi se adaptando [...].

A percepção de nossos entrevistados é clara em relação às melhorias que os novos tempos trouxeram consigo. $\mathrm{O}$ trabalho é mais facilitado em face das inovações tecnológicas, assim como o nível de conforto das casas com tudo o que a vida moderna é capaz de oferecer. Entrementes, essa realidade é plagada de contradições, na medida em que transforma completamente o modo de vida que hoje passa a ser governado pela frenética busca por rentabilizar o uso da terra e da força de trabalho familiar, que se torna cada vez mais escassa em função do reduzido número de filhos. Nos meios acadêmicos especializados é bastante conhecida a metáfora do treadmill de Cochrane ${ }^{[23]}$, segundo o qual, os agricultores vêem-se permanentemente obrigados à incorporação de novos processos e tecnologias, sob pena de serem expulsos da atividade. O ritmo é ditado pelas imposições do mercado, sendo eufemisticamente chamado de profissionalização da agricultura. No curso desse processo outras dimensões são afetadas, como revela o depoimento a continuação:

Antes era tudo natural, hoje é tudo à base de enlatado, nós até que procuramo fugir disso. O problema é como eu já disse antes, nós somo profissional do leite, e como falta mãode-obra pra nós, então nós não produzimos o feijão, a batata, a gente vai e compra esses produto, só que a gente vai ao supermercado, tu compra um produto com produtos químicos $e$ isso é difícil pra nós, porque se a gente tivesse mão-de-obra poderia plantá a batata, o feijão e seria muito melhor (grifos dos autores).

Esse depoimento denota o declínio da produção de autoconsumo como resultado das pressões que emanam das empresas e dos circuitos mercantis. As famílias intensificam a produtividade como forma de compensar o declínio dos preços dos produtos, fenômeno esse já detectado por Chayanov ${ }^{[24]}$ ao estudar o comportamento dos camponeses russos no início do século XX

Intensificar o ritmo de trabalho, ampliar a escala de produção e especializar-se 
em determinado tipo de cultivo ou criação é parte de um conjunto de transformações de grande envergadura. A incorporação dos bens de consumo duráveis propicia o conforto aos membros da família. Mas essas "comodidades" têm seu preço:

Naquele tempo não existia nem energia, não tinha televisão, geladeira, meio de comunicação, mão-de-obra era mais difícil, não tinha tratores, era tudo mais manual, as pessoas se judiavam mais o corpo do que hoje. Hoje, o trabalho é mais facilitado, mas se torna mais caro, o custo de vida é mais alto, as despesas são muito mais alta e o retorno é menor, devido a tantas despesas, é muita conta pra pagar.

O tempo dos pais era um tempo de restrições mas, por outra parte, o grau de mercantilização da vida rural não havia atingido níveis tão elevados quanto os de hoje. Destarte, a grande insatisfação brota do fato de que o produto do trabalho do colono não goza do reconhecimento esperado por parte da sociedade em geral. $\mathrm{O}$ abastecimento das cidades já não é mais atribuição das colônias, mas de uma complexa rede liderada pelos hipermercados e grandes superfícies de varejo. Elevam-se os custos de produção com o uso das inovações, mas o preço dos produtos agrícolas é cada vez mais baixo em face de uma concorrência que vem de dentro e de fora do país, além de outras dificuldades:

Nós como agricultores, eu acho que sofremos muito com a conseqüência do tempo, porque quando chove demais é problema, quando falta chuva é problema também [...]. Também a gente, com todo esforço, produz e quando tem em abundância, não tem mercado ou então os preços caem muito. E olhando pra trás parece que a gente recebia mais por esses produtos que tu vende hoje, mas o custo pra tu produzir é um custo a mais, tu trabalhas mais e ganhas menos, porque o lucro, hoje em dia, é mínimo.

Em nenhuma outra atividade agrícola o grau de implicações da mercantilização da agricultura é tão intenso quanto no caso do fumo, se temos em mente o fato de que muitas famílias estão deixando de produzir para o autoconsumo em face escassez de tempo e de mão-de-obra:

É muita ocupação [...] O fumo não deixa a gente cuidar de mais nada, é uma dedicação total, tem gente, como o meu sogro, que é 24 horas, porque ele cuida o fogo durante a noite da estufa... A gente não tá trabalhando 14 ou 15 horas por dia, a gente tá trabalhando 24 horas, tem pouco tempo pra descansar.

Eu sei que naquela época se comprava muito pouco de fora, quase que se consumia o que se tinha, arroz e tudo [...] $O$ que era mais necessário era açúcar, querosene e sal. Hoje se compra tudo, o pessoal vai à cidade e compra um pé de repolho, qualquer coisa e sai ali direto, muitas veiz vem de São Paulo, porque o pessoal compra. Todos têm propriedade, mas o fumo não nos deixa tempo pra nada, trabalha o ano inteiro em cima do fumo e quando termina de classificar, já tem canteiro, sementeira, semear de novo e nem terminou a safra passada e depois tem que fazer lenha pra queimar. Eu acho muito errado comprá essas coisa com veneno que podia ter em casa sem veneno.

$\mathrm{O}$ sentimento de impotência frente à falta de tempo para dedicar-se ao autoconsumo, não é visto como negativo apenas pelo fato de ferir a autonomia camponesa idealizada, mas porque a família passa a consumir produtos de procedência desconhecida, obtidos com o uso de 
agroquímicos, como revelou o depoimento acima.

As famílias que ingressaram no rumo da especialização produtiva vivem hoje uma realidade paradoxal. Se, por um lado, conquistaram um nível de desenvolvimento tecnológico razoável, vêem-se diante das incertezas dos mercados, das crescentes imposições das empresas às quais acham-se integrados e renunciam à possibilidade de produzir, ainda que parcialmente, o próprio alimento. O depoimento a seguir é de um agricultor que se especializou na produção de pêssego para as indústrias de conserva:

Batata eu compro no supermercado, eu não tenho vergonha de dizer isso. $O$ feijão eu compro do rapaz que planta aí na volta. Pra mim é mais vantagem o leite comprado de caixinha [...] Eu vou lá no supermercado e pego o leite de caixinha porque eu entendo que não tenho que me envolvê com essas coisa [...] Só galinha, ovo nós temo o ano todo, mas não quero mais porco, eu já tive porco, vaca e eu não quero pra mim, é só incômodo. O tempo que eu vô tratá um boi eu tô fazendo outro trabalho ... (grifos dos autores)

A erosão dos padrões culturais tradicionais dá lugar a reelaborações que buscam legitimar a opção, cada vez mais recorrente, de transferir aos mercados e a outrem a tarefa de suprir as necessidades alimentares dos membros da família.

Todavia, o acesso aos alimentos, para uma parcela significativa destas famílias, não se dá apenas pela via dos mercados locais, mas inclusive por uma atividade regular exercida por donos de camionetas que circulam pelas estradas rurais, vendendo tais produtos.
Eu plantei batata esse ano pro gasto e me arrependi. Mas é muito mais negócio ir ao mercado e comprar uns quilos que tu vai consumir [...]. O caminhão da feira passa aí na frente, é muito mais fácil eu comprar deles dois ou três reais de verdura do que cuidar uma horta, porque não vale a pena [...] É muito mais fácil comprar do que produzir.

O caminhão da feira, a que nosso entrevistado se refere, corresponde ao trabalho de comerciantes que residem no interior das comunidades e que vivem desse comércio itinerante nas cidades e no meio rural. $\mathrm{O}$ insólito recai no fato de que a clientela rural cresce a cada dia em face dos aspectos sublinhados anteriormente.

As práticas de autoconsumo justificarse-iam quando se anseia consumir um produto seguro, em termos da ausência de contaminantes, ou em virtude de qualidades intrínsecas que aquele adquirido fora não as possui. Essa é a posição das famílias dedicadas à produção ecológica de frutas e hortaliças, assistidas por organizações nãogovernamentais da região:

Horta, ovos, carne, leite, tudo isso é daqui de casa, tanto carne bovina, frango, como galinha caipira [...] Eu acho que não se economiza, se tem pelo fato de ser mais saudável, mas não que isso traga um retorno econômico, isso não, porque no caso ovos e essas galinha, na verdade, comem mais do que a gente fosse ao mercado.

A análise de representações sobre identidade camponesa consistiu no objeto de estudo de trabalho desenvolvido por Seyferth no Vale do Itajaí-Mirim, estado de Santa Catarina. A investigação evidenciou a oposição existente, no imaginário de comunidades teuto-brasileiras, entre colonos 
fortes e colonos fracos. Os primeiros são tomados como modelo do camponês ideal, ou seja, "aquele que possui a propriedade de terras suficientes para se reproduzir sem que um dos membros tenha de recorrer a alguma atividade assalariada". Com efeito, "são, portanto, os «verdadeiros» camponeses porque têm uma só ocupação: a agricultura ou, mais especificamente, a policultura, ${ }^{\text {,[1]]. }}$

Coincidimos com Seyferth em relação ao peso das ambigüidades que encerra tal noção no plano das representações e práticas adotadas pelos indivíduos. Entrementes, deixamos claro que há um conjunto de evidências que conspiram para uma crise muito mais profunda, envolvendo a erosão de certos valores relativos a uma dimensão essencial que identificava todo um estilo de vida, responsável por forjar uma sociabilidade singular no Sul do país. Esses colonos, admitidos como expressão cristalina dos valores de uma cultura tipicamente camponesa, se distanciam, consideravelmente, do agricultor familiar que emerge no contexto da realidade contemporânea.

Encontramo-nos, portanto, diante de uma das dimensões que identificam a crise de expectativas engendrada fundamentalmente pelos impactos advindos da mercantilização da vida rural, com seus inúmeros desdobramentos. No limite, nosso estudo buscou estabelecer a conexão existente entre a modernização, em sentido amplo, com a invalidação e deslegitimação de um conjunto de saberes e práticas ligadas à produção do autoconsumo em toda sua diversidade.

\section{Considerações finais}

Recentes trabalhos ${ }^{[25,26]}$ não deixam dúvidas de que a fome manifesta-se de forma mais intensa nos espaços rurais em relação aos urbanos. Nos Estados meridionais do Brasil ela é muito menos grave que nas demais regiões, o que não pode ser visto como uma questão desprovida de relevância, em que pese o fato de aproximadamente 1,053 milhão de domicílios rurais vivenciarem situações de insegurança alimentar (leve, moderada ou grave), nessa parte do país, segundo as estatísticas mais recentes ${ }^{[27]}$.

Buscou-se chamar a atenção, nesse artigo, para o fato de que existe um quadro de transformações bastante amplo que incide sobre os espaços rurais no Sul do Brasil, particularmente sobre as comunidades do interior dos municípios de Pelotas, São Lourenço do Sul e Canguçu. Nesse contexto, alertamos para os efeitos engendrados pela especialização produtiva, que levou à supressão da policultura e da diversificação nos estabelecimentos rurais, assim como a intensificação dos processos produtivos, traduzida na busca frenética por incrementar a produtividade e, consequentemente, a produção dos cultivos e criações.

Paralelamente, estas famílias rurais passam a depender de uma única fonte de ingresso monetário e o esforço por potencializar o incremento de suas fontes de renda, obriga-as a rentabilizarem os recursos disponíveis, sendo essa a tradução emblemática do que a literatura internacional passou a denominar de mercantilização da agricultura, magistralmente descrita nos trabalhos realizados por Ploeg ${ }^{[28,29]}$, entre 
outros estudos. Nesses trabalhos, aparece evidenciado o fato de que o desenvolvimento da agricultura esteve associado a uma profunda transformação de sua base técnica, sendo que o mercado é guindado à condição de principal mecanismo regulador dos processos produtivos e da vida social no meio rural.

No Brasil, o período coincidente com a modernização conservadora (1965-1980), é marcado pelo aprofundamento da mercantilização da agricultura e da vida rural, que trouxeram consigo, inúmeros desdobramentos. A simplificação do sistema de culturas, a especialização e intensificação produtiva e o produtivismo são vistos como implicações diretas de um fenômeno no qual a perda de autonomia das famílias é incontestável, conferindo-lhes uma posição subordinada e cada vez mais vulnerável em relação aos mercados.

O estudo aqui apresentado indica que a intensificação, a especialização produtiva e a mercantilização da agricultura e do mundo rural, conjuntamente, conspiram para um cenário marcado pelo esvaziamento das práticas de autoconsumo. Claro está que esse fenômeno não pode ser explicado exclusivamente por esses grandes vetores. A mudança nos hábitos de consumo, a redução da mão-de-obra disponível nos estabelecimentos familiares decorrente da redução do número de filhos figuram, entre outros fatores, como fortalecedores dessa tendência.

Alguns dos depoimentos sinalizaram claramente nessa direção, mostrando que a força de trabalho, cada vez mais reduzida, é crescentemente deslocada para atender a demanda da atividade comercial dominante, reduzindo a disponibilidade de mão-de-obra para a produção de autoconsumo. Também há que alertar para as imposições de empresas que por razões de ordem técnica e, sobretudo sanitárias, impedem as famílias de manterem criações destinadas ao autoconsumo.

A pesquisa detectou os impactos da pressão exercida sobre produtores que se converteram em "agricultores profissionais", os quais manifestam, tacitamente, o abandono progressivo dos cultivos e criações de subsistência. Os aludidos traços do ethos camponês, objeto de referência na literatura especializada, parecem bastante minimizados na condição desse agricultor familiar moderno, cuja dinâmica é agora ditada pelo peso da mercantilização.

Mas é preciso deixar claro que o fato das famílias rurais adquirirem externamente os produtos alimentares, cada vez com maior intensidade e frequiência, não implica supor que os indivíduos a elas ligados vivenciem situações de insegurança alimentar e nutricional.

A realização da pesquisa permitiu detectar as ambigüidades do discurso dos entrevistados ao referirem-se à qualidade dos produtos adquiridos externamente (no comércio local ou através dos atravessadores) vis a vis com o que é gerado no próprio estabelecimento. Nesse contexto, é cada vez mais reduzido o número de famílias que optam por preservar essas práticas, no afã de garantir a qualidade do que consomem na propriedade.

Compreender esses aspectos torna-se fundamental para discutir a segurança 
alimentar e nutricional em suas distintas dimensões. Esse entendimento pode significar a incorporação de outros compromissos, para além de medidas de caráter imediatista, que reiteradamente renunciam à tarefa de resgatar o valor material e simbólico das práticas de autoconsumo, tanto no âmbito rural quanto urbano.

Por fim, há um aspecto que merece ser aqui destacado. Com efeito, se comida é identidade, ela se reconstrói sob novas bases que, necessariamente, apontam para o gradual distanciamento de um sistema de valores que não se sustenta, a não ser de forma idealizada e diferida, no cotidiano das famílias rurais de comunidades coloniais do extremo sul do Rio Grande do Sul. Claro está que esse fenômeno se descortina de forma heterogênea, assumindo contornos e ritmos bastante diferenciados no espaço social mais amplo do Brasil meridional.

\section{Referências}

[1] Candido A. Os parceiros do Rio Bonito. São Paulo: Livraria Duas Cidades; 1987.

[2] Schneider S A pluriatividade na agricultura familiar. Porto Alegre: Ed. da UFRGS; 2003.

[3] Gasson R. e Errington, A The Farm Family Business. Cab International: Wallingford; 1993.

[4] Seyferth G. Herança e Estrutura Familiar Camponesa. Boletim do Museu Nacional. R. Janeiro: N.S. Antropologia;1985; 52.

[5] Woortmann E Herdeiros, parentes e compadres. São Paulo: Hucitec; 1995.

[6] Lamarche H. (coord.) A Agricultura Familiar. Comparação Internacional - Uma
Realidade Multiforme. (trad. Tijiwa A.) Campinas: Ed. UNICAMP; 1993.

[7] Wanderley MNB. Raízes históricas do campesinato brasileiro. In: Tedesco (org.) Agricultura familiar: realidades $e$ perspectivas. Passo Fundo: EDIUPF; 1999; 23-56.

[8] Leite S. Autoconsumo y sustentabilidad en la agricultura familiar: una aproximación a la experiencia brasileña. In: Belik W. (org): Políticas de seguridad alimentaria y nutrición en América Latina, São Paulo: Hucitec; 2004; 123-64.

[9] Woortmann K. Com parente não se neguceia: o campesinato como ordem moral. Brasília: Série Antropológica; 1990; 88: 83-4.

[10] Garcia Jr AR. O Sul: Caminho do Roçado - estratégias de reprodução camponesa e transformação social. São Paulo: Marco Zero; 1990.

[11] Seyferth G. As Contradições da Liberdade: análise de representações sobre a identidade camponesa. Revista Brasileira de Ciências Sociais. R. de Janeiro, 1992; 18(7): 78-95.

[12] Mintz SW. Comida e Antropologia: uma breve revisão. In: Revista Brasileira de Ciências Sociais; 2001; 16(47): 31-42.

[13] Bourdieu P. La Distinction. Critique sociale du jegement. Paris: Minuit; 1979.

[14] Banco de dados da agricultura familiar. [base de dados na Internet] Brasília: Ministério do Desenvolvimento Agrário, Instituto Nacional de Colonização e Reforma Agrária Incra/SADE [acesso em 2007 Abr]. Disponível em: http://www.incra.gov.br/sade/default.asp. 
[15] Seyferth G. A Colonização Alemã no Vale do Itajaí-Mirim: um estudo de desenvolvimento econômico. Porto Alegre: Movimento; 1974.

[16] Roche J. A colonização alemã e o Rio Grande do Sul. Porto Alegre: Ed. Globo; 1969.

[17] Grando MZ. Pequena Agricultura em Crise: o caso da colônia francesa no Rio Grande do Sul. Porto Alegre: FEE; 1990.

[18] Van Der Ploeg JD. O modo de produção camponês revisitado. In: Schneider, S. (org) $A$ Diversidade da Agricultura Familiar, Porto Alegre: UFRGS; 2006; 13-54.

[19] Afubra [homepage na Internet]. Santa Cruz do Sul. Associação dos Fumicultores do Brasil [acesso em 2008 Maio]. Disponível em: http://www.afubra.com.br/principal.php.

[20] Paulilo MIS. Produtor e Agroindústria: Consensos e Dissensos. O caso de Santa Catarina. Florianópolis: UFSC; 1990.

[21] Almeida MWB. Redescobrindo a família rural. In: Revista Brasileira de Ciências Sociais. Rio de Janeiro;1986; 1(1): 66-83.

[22] Group Doux. [homepage na Internet]. Montenegro: Doux Frangosul [acesso em 2008 Maio]. Disponível em: http://br.doux.fr/.

\section{Agradecimentos}

Os autores agradecem o apoio do $\mathrm{CNPq}$ pela concessão de bolsa de produtividade e de bolsa de doutoramento, sem o qual esse trabalho não poderia haver sido realizado.
[23] Cochrane WW. The development of american agriculture - A historical analysis. University of Minneapolis Press, Minneapolis; 1979.

[24] Chayanov, AV. La Organización de la Unidad Económica Campesina. $1^{a}$ ed. Buenos Aires: Nueva Visión; 1974.

[25] Graziano da Silva J, Tavares L. Segurança alimentar e a alta dos preços dos alimentos: oportunidades e desafios. In: Segurança Alimentar e Nutricional, Campinas, 15(1), p. 62-75; 2008.

[26] Hoffmann R. Determinantes da Insegurança Alimentar no Brasil: Análise dos Dados da PNAD de 2004. In: Segurança Alimentar e Nutricional, Campinas; 200815(1): 49-61.

[27] Brasil. Instituto Brasileiro de Economia e Estatística. Pesquisa Nacional por Amostra de Domicílios: Segurança Alimentar. 2004. Rio de Janeiro: MDS; 2006.

[28] Van Der Ploeg JD. Labor, markets, and agricultural production. Boulder/San Francisco/Oxford: Westview Press, 1990.

[29] Van Der Ploeg, JD. El proceso de trabajo agrícola y la mercantilización. In: Guzmán, ES; Gonzáles de Molina, M (eds.). Ecología, campesinado e historia. Madrid: Las ediciones de la piqueta; 1992; 153-95. 